anales de psicología / annals of psychology

2020, vol. 36, $\mathrm{n}^{\circ} 3$ (october), 475-482

https://doi.org/10.6018/analesps.394021
(C) Copyright 2020: Editum. Servicio de Publicaciones de la Universidad de Murcia. Murcia (Spain) ISSN print edition: 0212-9728. ISSN online edition (http://revistas.um.es/analesps): 1695-2294

Online edition License Creative Commons 4.0: BY-SA

\title{
Factorial analysis and invariance by sex and age of the Anger Rumination Scale ARS Spanish version
}

\author{
Ronald Toro*, Juan García-García, and Flor Zaldívar-Basurto
}

University of Almeria (Spain)

\begin{abstract}
Título: Análisis factorial e invarianza por sexo y edad de la Anger Rumination Scale (Escala de Rumiación de la Ira) versión española.

Resumen: La rumiación ira es pensamiento perseverativo sobre un evento personalmente significativo ocurrido a la persona o las demás que conlleva a la ira y se constituye como factor de riesgo para la agresión. El objetivo fue determinar la estructura factorial y comprobar la invarianza por sexo y edades de la Anger Rumination Scale [ARS]. Se conformó una muestra no probabilística de 630 personas con entre 18 y 63 años $(M=31.07, D T=$ 11.27), agrupadas por sexos (252 hombres, 378 mujeres) y edades (278 menores de 25 años, 352 mayores de 25 años). Los instrumentos utilizados fueron el ARS y el cuestionario de agresión reactiva y proactiva RPQ. Se encontró que el ARS presenta un ajuste favorable en un modelo de cuatro factores correlacionados con covarianzas residuales. A su vez, resultó invariante entre sexos y edades luego de imponer restricciones progresivas en el modelo confirmado, y presentó correlaciones significativas con la agresión reactiva y proactiva como evidencias de la validez de criterio concurrente. Se concluyó que la ARS presenta indicadores adecuados de fiabilidad y validez para ser usado en el contexto colombiano.
\end{abstract}

Palabras clave: Rumiación; Ira; Agresión; Análisis factorial; Invarianza.

\section{Introduction}

Anger rumination is a persevering thought about a personally significant event that has occurred to the person or others that leads to anger, is constituted as a risk factor for aggression and involves prefrontal and subcortical regions related to self-referential information processing, social cognition, and emotional regulation associated with difficulty in thought suppression and behavioral self-control (Denson, 2012). This construct is theoretically supported by three processes: memories of anger experiences -activators-, attention to immediate experiences of anger -intensifiers-, and thoughts after anger -actuators-, all associated with the duration of the anger experience and the tendency to stay in it (Sukhodolsky, Golub, \& Cromwell, 2001).

Psychopathological studies have reported that anger rumination constitutes a risk factor for trait and mood anger according to longitudinal follow-ups (Takebe, Takahashi, \& Sato, 2016), also, it is associated with proactive and reactive aggressive behavior mediated by moral dissociation (Wang et al, 2018), an intentional control as low self-regulation (White \& Turner, 2014), and allows predicting the tendency to aggression from emotional dysregulation (Martino et al., 2015), since it is considered a mediator between emotional intelligence and physical, verbal and indirect aggression (GarcíaSancho, Salguero, \& Fernández-Berrocal, 2016). Secondary

* Correspondence address [Dirección para correspondencia]: Ronald Alberto Toro Tobar. Av. Caracas \#46-72, Bogotá (Colombia).

E-mail: tororonald@gmail.com, rtt711@inlumine.ual.es

(Article received: 27-8-2019; revised: 16-10-2019; accepted: 9-1-2020)
Abstract: Anger rumination is persevering thoughts about a personally significant event that occurred to the person or others that leads to anger and constitutes a risk factor for aggression. The objective was to determine the factor structure and test the invariance by sex and age of the Anger Rumination Scale [ARS]. A non-probabilistic sample of 630 persons between 18 and 63 years old was formed $(M=31.07, S D=11.27)$, grouped by sex ( 252 men, 378 women) and age ( 278 under 25 years old, 352 over 25 years old). The instruments used were the ARS and the reactive and proactive aggression RPQ questionnaire. We found the ARS to have a favorable fit in a four-factor model correlated with residual covariances. In turn, invariance between sexes and ages was found after imposing progressive restrictions in the confirmed model, and it showed significant correlations with reactive and proactive aggression as evidence of the validity of concurrent criteria. We concluded that the ARS shows adequate indicators of reliability and validity to be used in the Colombian context.

Keywords: Rumination; Anger; Aggression; Factorial analysis; Invariance. psychopathy and the relationship with reactive and proactive aggression have also been reported to be high in young adults (Guerra \& White, 2017).

These reports show that anger rumination seems to have a mediating role between different causal variables (structural and functional), anger responses and proactive and reactive aggressive behaviors, results that support the transdiagnostic capacity of this variable and its usefulness in the development of advances in the explanation of antisocial and criminal behaviors (du Pont, Rhee, Corley, Hewitt, \& Friedman, 2017; McLaughlin, Aldao, Wisco, \& Hilt, 2014). However, further research is needed to expand these findings, including measurements of rumination anger with psychometric instruments recognized for their accuracy and their discriminatory or convergent capabilities in different populations.

\section{The instrument in this study}

The Anger Rumination Scale [ARS] (Sukhodolsky et al., 2001) was developed to measure anger rumination conceptualized in a multidimensional way, starting from the tendency to focus attention on anger, remembering episodes of anger, and thoughts on the causes and consequences of anger episodes were proposed items of the ARS. Using a sample of 408 participants, in the Exploratory Factor Analysis (CFA) the scale obtained an end solution of four correlated factors: Thoughts of Revenge (TR), After Anger Thoughts (AA), Memories of Anger (AM), and Understanding the Causes of Anger (UC). The original version showed favorable confirmatory factorial adjustment indicators (Root Mean Square Residual $\mathrm{RMR}=0.04$, Goodness of Fit Index GFI $=0.87$, 
Comparative Fit Index CFI = 0.95); additionally; the authors suggested adding residual covariances between items 8 and 9, 11 and 12 according to the modification rates with which they obtained an increase in the final adjustment indicators. This version showed a high internal consistency according to Cronbach's alpha coefficient in the full scale $(\alpha=.93)$ and subscales (TR $\alpha=.72, \mathrm{AA} \alpha=.86, \mathrm{AM} \alpha=.85$, and UC $\alpha=$ $.93)$.

The ARS has been revised in different countries with factorial structures equal to the original, among them is the Iranian version $(\mathrm{GFI}=0.91$, Non Normed Fit Index NNFI $=$ 0.93 , IFC $=0.95$, Root Mean Square Error of Approximation RMSEA $=0.06$ ), in which they added residual covariances between items 9 and 18, 11 and 12 (Besharat, 2011), the French version with optimal confirmatory adjustment values $(\mathrm{CFI}=0.96$, RMSEA $=0.058)$ (Reynes, BerthouzeAranda, Guillet-Descas, Chabaud, \& Deflandre, 2013) and Turkish with similar structural indicators $(\mathrm{CFI}=0.90, \mathrm{GFI}=$ 0.90, RMSEA $=0.06$, SRMR $=0.05)($ Satici, 2014). In Great Britain and China, a cross-cultural study in which the factor structure was verified through an AFC of the English language version and the Chinese translation, after imposing modifications on the model (including correlations between the residuals of items 11 and 12, and 18 and 19), a satisfactory fit was obtained for the original four-factor solution, although the goodness-of-fit indices were slightly lower in the Asian sample $(\mathrm{RMR}=0.04$ and 0.06 , GFI $=0.93$ and 0.91 , $\mathrm{CFI}=0.95$ and 0.88, RMSEA $=0.06$ and 0.06) (Maxwell, Sukhodolsky, Chow, \& Wong, 2005).

In Ibero America, ARS has been adapted to the Spanish and Portuguese languages. In Spain, a final solution of four correlated factors, with appropriate indicators of adjustment in the CFA, was obtained after imposing residual covariances between items 11 and 12 following the original instrument $(\mathrm{CFI}=.92$, Tucker-Lewis Index TLI $=.90, \mathrm{RMSEA}=.06$, SRMR $=.05)$; in terms of reliability, a favorable internal consistency was obtained in the total scale $(\alpha=.89)$ and acceptable in all subscales except AA and AM (TR $\alpha=.67$, AA $\alpha=.83, \mathrm{AM} \alpha=.78$, and UC $\alpha=.64$ ) (Magán-Uceda, Lozano-Bleda, Pérez-Nieto, Sukhodolsky, \& Escalona-Martínez, 2016).

In turn, the ARS in Mexico adapted to the four-factor model with residual covariances between items 1 and 2, concerning the other revised theoretical models based on the original instrument (Sukhodolsky et al., 2001). The onedimensional model with which they explored (model 1) then saturated the four known factors; the original four-factor correlated model and one resulting modified according to the rates of modification (model 2 and 3), the three-factor correlated model -AM, AA, TR+UC as the cognitive dimension of what could have been done to the anger response (model 4)-, and two two-factor correlated models: a) $\mathrm{TR}+\mathrm{UC}$ as a counterfactual thinking and $\mathrm{AM}+\mathrm{AA}$ as a temporal dimension (model 5), and b) TR as a behavioral dimension and the combination $\mathrm{UC}+\mathrm{AA}+\mathrm{AM}$ as a cognitive dimension (model 6 ). The final adjustment values reported for the Mexican version of the ARS were favorable for the original model correlated with covariances between errors (CFI $=0.89$, SRMR $=0.92$, RMSEA $=0.06)$ (Ortega-Andrade, Alcázar-Olán, Matías, Rivera-Guerrero, \& Domínguez Espinosa, 2017).

These findings seem to show that a similar correlated four-factor structure can be replicated in Latin American countries, and studies on this subject, except in Mexico, have not yet been carried out with different samples from other countries.

At the differential level, rumination anger scores appear to change between males and females. In the development of ARS, variations in the scores obtained were reported, with elevations in males on the TR scale $(t(406)=5.37, p<.001)$, while in age there was no significant correlation $(r=-0.12)$ (Sukhodolsky et al., 2001). In turn, the British and Chinese adaptations used a MANOVA to identify variations by sex and culture of origin, and found significant male variations in the TM scale $(F(1,944)=17.22, p<.001), \mathrm{AM}(F(1,944)=$ $9.57, p<.01)$ and total ARS $(F(1,944)=7.19, p<.01)$, age showed significant positive correlations with the AA, TR, and ARS scales $(r=.20, .33$, and .19, $p<.01$ ) (Maxwell et al, 2005). In the Spanish adaptation, similar differential results in sex were reported in TR $(F(1,382)=14.91, p<.0005)$ and $\mathrm{AM}(F(1,382)=5.16, p<.05)$, but they were not significant for age $(F(8,758)=.68, p=.71)$ (Ortega-Andrade et al., 2017).

These differences in ARS scores, apparently evident between the male and female sexes, have not been analyzed based on their factor structure and invariant capacity, as they are with ages, in which adults versus adolescents may vary their anger rumination responses and their capacities to regulate anger (Wong, Konishi, \& Zhao, 2018). The common feature of these reports is a lack of the invariance analysis factor, in which the variations in measurement between the groups compared are much more accurately reflected, by considering their factor saturations and intercepts, and are not limited to changes in the mean test scores in each group (Meredith, 1993).

Taking into account the above, the objective of this study was to analyze the factor structure of the theoretical models previously analyzed with samples from Spain and Mexico, and the invariance according to sex and age of the ARS in a Colombian sample. Additionally, we sought to investigate the validity of the convergent criterion of the ARS with reactive and proactive aggression as indicators of the explanatory capacity of the test as a criterion variable and additional evidence of construct validity.

\section{Method}

\section{Participants}

There were 630 Colombians selected through an incidental non-probabilistic sampling (5\% error margin and 95\% confidence interval), distributed in $60 \%$ female $(n=378)$ and 
$40 \%$ male $(n=252)$, mainly single $(60 \%, n=378)$ and married $(20 \%, n=126)$, with a high school education level $(20 \%$, $n=126)$, intermediate (23). $3 \%, n=147)$ and above $(49.4 \%, n$ $=311)$ and an average age of 31.07 years $(S D=11.27$; range between 18 and 63).

In order to perform the invariance analysis, the sample was divided into two groups according to the age and sex of each participant distributed as (a) under 25 years old $(n=$ $278)$, single $(87.4 \%, n=243)$, with a higher education level $(52.2 \%, n=145)$ and a mean age of 21.57 years $(S D=2.08)$, versus (b) over 25 years $(n=352)$, single $(38.4 \%, n=135)$ and married $(34.7 \%, n=122)$, with a high school education level $(21.3 \%, n=75)$, technical $(22.7 \%, n=80)$ and higher $(47.2 \%, n=166)$ and an average age of 38.57 years $(S D=$ 9.82).

The distribution by sex is: (a) men $(n=252)$, single $(60.3 \%, n=152)$ and married $(21.4 \%, \mathrm{n}=54)$, with a high school education $(20.6 \%, n=52)$, technical $(25.4 \%, n=64)$ and higher $(44.8 \%, n=113)$ and an average age of 31.20 years $(S D=10.86)$, versus women $(n=378)$, single $(59.8 \%, n$ $=226)$ and married $(19 \%, n=72)$, with a high school education $(19.6 \%, n=74)$, technical $(22 \%, n=83)$ and higher education $(52.4 \%, n=198)$ and an average age of 30.98 years $(S D=11.55)$.

\section{Instruments}

The Anger Rumination Scale [ARS] (Sukhodolsky et al., 2001)

Scale designed to evaluate anger rumination based on attention to thoughts and memories of anger experiences, contains 19 Likert-type reagents ranging from 1 ("Almost never") to 4 ("Almost always"), which make up four subscales: Revenge thoughts (4 items, $\alpha=.72$ ), thoughts after anger (6 items, $\alpha=.86$ ); anger memories (5 items, $\alpha=.85$ ), and understanding causes ( 4 items, $\alpha=.77$ ). In this study, the Spanish version was used (Ortega-Andrade et al., 2017), which obtained internal consistency coefficients similar to the original (ARS $\alpha=.71, \mathrm{AA} \alpha=.89, \mathrm{TR} \alpha=.78, \mathrm{AM} \alpha=.72, \mathrm{UC}$ $\alpha=.75)$.

\section{Reactive-Proactive Aggression Questionnaire [RPQ] (Raine et al., 2006)}

It is a self-applied questionnaire to identify reactive aggression (high emotional activation, impulsiveness, hostility), and proactive (instrumental, planned, low empathy and cold strategy). The RPQ contains 23 items that are scored on a three-value Likert-type scale: never (0), sometimes (1), and often (2). In this study we used the Spanish adaptation (Andreu, Peña, \& Ramírez, 2009), which obtained a favorable internal consistency according to the total Cronbach's Alpha coefficient of $\alpha=.91$, for reactive aggression a $\alpha=.84$ and for proactive aggression a $\alpha=87$. The reliability values of the RPQ in this study were favorable according to the coefficient $\alpha=.878$ and $\omega=.888$. Similarly, for the reactive $(\alpha=$
.819 and $\omega=.821)$ and proactive $(\alpha=.801$ and $\omega=.827)$ subscales of aggression.

\section{Procedure}

Three phases of the psychometric study were carried out. The first one consisted of an open call for participation in the research in natural persons of different socioeconomic and educational levels, to guarantee the heterogeneity of the data to be obtained. The second phase was data collection, in which it was guaranteed that all persons agreed to participate voluntarily by signing the informed consent; the team of researchers was available for the resolution of possible doubts. The instruments were applied in a printed version on site. Finally, in the third phase, the answers were tabulated in the Excel database and the documents were kept in confidential custody.

As far as ethical considerations are concerned, the ethical standards and rights of participants such as well-being according to the Declaration of Helsinki (Asociación Médica Mundial [WMA], 2017) were guaranteed, ensuring through informed consent that the handling of personal data for research purposes, the confidentiality and handling of the data provided and the results obtained from the study will be safeguarded according to internationally required protocols.

\section{Statistical and Psychometric Analysis}

The analysis of the data was performed with the program R-Project (RStudio Version 1.2.1335) with the lavaan package 0. 6-4 (Rosseel, 2012). The Confirmatory Factor Analysis (CFA) was carried out using the maximum likelihood estimation method that makes it possible to compare the adjustment indexes of several factorial models; likewise, the multifactorial indicators were analyzed based on structural equations (Structural Equation Modeling, SEM), which are procedures that make it possible to review the underlying theoretical models, according to the structure of the data adjusted to the previous theoretical assumptions (Kahn, 2006). In the $\mathrm{CFA}$, we further reviewed the Satorra-Bentler's chi-square approximation of goodness-of-fit $\left(\mathrm{S}-\mathrm{B} \chi^{2}\right)$, the Comparative Fit Index (CFI) and the Tucker Lewis Index (TLI), in which values greater than .90 are expected as favorable, also the RMSEA, with a $90 \%$ confidence interval (IC90\%), in which values less than .08 are expected (Hu \& Bentler, 1999). In comparing the models reviewed, one of the recommended methods for selecting the best-confirmed model within different alternatives has been the Akaike's information criterion (AIC) and the Bayesian information criterion (BIC) (LiChung, Po-Hsien, \& Li-Jen, 2017).

Once the structure of the ARS was confirmed, the factor invariance analysis was done for the male, female, under and over 25 groups. We started with the configural invariance in which we sought to check that the factor structures between the groups are equivalent in the groups; then in the metric invariance we sought to check whether the test was invariant 
in the factor loads of the nested groups, then in the strong invariance an additional progressive restriction was imposed on the intercepts to check whether the test is not invariant at the scalar level, i.e. whether the response profiles and ARS structure are not similar between the nested groups. Finally, in strict invariance, a progressive restriction was imposed on the intercepts as well as on the variances and covariances between the errors, to identify whether the differences in responses between the groups of items are not due solely to the differences obtained between the latent factors (Byrne, 2008). The reference values were obtained from the variations $\Delta \mathrm{S}-\mathrm{B} \chi^{2}$, between the factor models for each group nested in the CFI with a cut-off point of $\Delta$ CFI $=\leq 0.01$, given that "a value less than or equal to -0.01 indicates that the null hypothesis of invariance should not be rejected" (Chung \& Rensvold, 2002, p. 251) and a $\Delta$ RMSEA $\leq 0.015$, to accept the invariance between each progressive constraint (Chen, 2007).

Subsequently, as evidence of the concurrent validity of the ARS, it was established that anger rumination is a significant predictor of reactive and proactive aggression as criterion variables (Anestis, Anestis, Selby, \& Joiner, 2009), based on hypothesis testing with Pearson's correlations and multiple linear stepwise regressions, in which variations in $\mathrm{R}^{2}$ and $\beta$ coefficients were analyzed with a $95 \%$ confidence interval, these values would indicate the predictive ability of rumination dimensions on aggressive behaviors.

\section{Results}

The preparation of the data set for multivariate analysis was done by reviewing the Mardia Coefficient for a cut-off point of less than three to assume multivariate normality of the data set $(z=1.96)$, a value of 80.04 was obtained $(p<.001)$, by which it assumed non-normality due to the high multivariate kurtosis (Yuan, Marshall, \& Bentler, 2002). Because of this, the analyses were executed with the Satorra-Bentler scaled comparatives (S-B $\chi 2$ ), which have been recommended for this type of distributions (Satorra \& Bentler, 2010), composed of scales with several response options (Rhemtulla, Brosseau-Liard, \& Savalei, 2012).

\section{Confirmatory factorial analysis of the ARS}

The approximation values of the standard errors were used as fit indicators for each proposed model. It is recommended that the combined RMSEA and SRMR values be reviewed to avoid rejecting models that indicate a good fit (Hu \& Bentler, 1999); thus, Table 1 shows the goodness-offit indexes obtained for each model evaluated. This study shows that the one-dimensional model showed the least favorable adjustment indicators compared to the other models evaluated. For the others, to identify the best statistically valued, goodness of adjustment was estimated using the Akaike Criterion (AIC) and its Bayesian Information Criterion [BIC] (Yang, 2003), in this case, the four-dimensional model correlated AM, AA, TR, and UC with residual covariances items 11 ("I analyze events that make me angry") and 12 ("I think about the reasons why people treat me badly") (Sukhodolsky et al., 2001); however, once the rates of modification have been reviewed by implementing residual covariances between the items of each factor, theoretically viable or suggested in adaptations of the test, all within the indicators of the same latent variable, by adding a residual covariance between item 10 ("I have had moments when I could not stop worrying about a particular conflict") and item 16 ("When someone makes me angry I cannot stop thinking about how to get back at this person"), an additional, re-specified model 3a was obtained, in which the adjustment indicators were much more favorable for the instrument structure.

Table 1. Goodness-of-fit indices for the models of ARS assessed $(\mathrm{n}=630)$.

\begin{tabular}{|c|c|c|c|c|c|c|c|c|c|}
\hline Model & $\chi^{2}$ & S-B $\chi^{2}$ & Df & CFI & TLI & RMSEA (IC90\%) & SRMR & AIC & $\mathrm{BIC}$ \\
\hline $\begin{array}{l}\text { Model } 1 \text { (ARS one-dimensional; Sukhodolsky et al., } \\
\text { 2001). }\end{array}$ & $944.882^{* * *}$ & $579.148^{* * *}$ & 152 & 0.874 & 0.859 & $0.083(0.076-0.091)$ & 0.054 & 24801.134 & 25054.540 \\
\hline $\begin{array}{l}\text { Model } 2 \text { (four-dimensional and correlated: AM, AA, } \\
\text { TR, and UC; Sukhodolsky et al., 2001). }\end{array}$ & 538.869 *** & $358.571 * * *$ & 146 & 0.940 & 0.929 & $0.059(0.051-0.067)$ & 0.044 & 24447.121 & 24727.202 \\
\hline $\begin{array}{l}\text { Model } 3 \text { (four-dimensional and correlated: AM, AA, } \\
\text { TR, and UC with residual covariances between items } \\
11 \text { and } 12 \text {; Sukhodolsky et al., 2001). }\end{array}$ & 524.096 *** & $349.370^{* * *}$ & 145 & 0.942 & 0.932 & $0.058(0.050-0.066)$ & 0.043 & 24434.348 & 24718.874 \\
\hline $\begin{array}{l}\text { Model 3a (four-dimensional and correlated: AM, AA, } \\
\text { TR, and UC with residual covariances between items } \\
\text { 11-12; Sukhodolsky et al. (2001), and items 10-16). }\end{array}$ & $468.591 * * *$ & $314.364^{* * *}$ & 144 & 0.952 & 0.943 & $0.053(0.045-0.061)$ & 0.041 & 24380.843 & 24669.815 \\
\hline $\begin{array}{l}\text { Model } 4 \text { (three-dimensional correlated AM, AA, and } \\
\text { TR+UC; Ortega-Andrade et al., 2017). }\end{array}$ & $571.337 * * *$ & $376.732^{* * *}$ & 144 & 0.933 & 0.921 & $0.062(0.055-0.070)$ & 0.043 & 24483.589 & 24772.561 \\
\hline $\begin{array}{l}\text { Model } 5 \text { (two-dimensional correlated AM+AA and } \\
\text { TR+UC; Ortega-Andrade et al., 2017). }\end{array}$ & $668.113^{* * *}$ & $433.832^{* * *}$ & 146 & 0.916 & 0.902 & $0.069(0.062-0.077)$ & 0.047 & 24576.365 & 24856.445 \\
\hline $\begin{array}{l}\text { Model } 6 \text { (two-dimensional correlated TR and } \\
\text { AM+AA+UC; Ortega-Andrade et al., 2017). }\end{array}$ & $589.512^{* * *}$ & $386.300^{* * *}$ & 146 & 0.931 & 0.919 & $0.063(0.056-0.071)$ & 0.043 & 24497.764 & 24777.845 \\
\hline
\end{tabular}

Note: $\chi^{2}$ (Chi-square approximation of goodness-of-fit), $S-B \chi^{2}$ (Satorra-Bentler's chi-square approximation of goodness-of-fit), $d f$ (Degrees of Freedom), $C F I$ (Comparative Fit Index), TLI (Tucker Lewis Index), RMSEA (Root Mean Square Error Aproximation), IC90\% (Confidence Interval), SRMR (Standarized Root Mean Square), AIC (Akaike's information criterion), BIC (Bayesian Information Criterion). $* * * p<.001$ 


\section{Invariance by sex and age of the ARS}

The model that showed the best adjustment indicators was the one with the four factors correlated with residual covariances. Subsequently, we reviewed each nested group of participants (male vs. female, over and under 25 years old) using this confirmed structure (model $3 \mathrm{a}$ ), imposing progressive and sequential restrictions to analyze the configural, metric, scalar and strict invariance.

The values $\chi^{2}$ and S-B $\chi^{2}$ with a significance $p<.001$ in the conformed groups appear in table 2 ; these results suggest that the models should be rejected because of the statistically significant differences that are evident between the hypothetical models obtained in each group; however, this indicator has been questioned because of its sensitivity to the sample size, therefore, the conclusions based only on this indicator can lead to rejecting parsimonious and theoretically acceptable models, it is recommended in this respect, the analysis of the progressive variations for each of the restrictions $(\mathrm{Hu} \&$ Bentler, 1999). The R-CFI, R-TLI, R-RMSEA, and SRMR values in Table 2 indicate optimal adjustments for all groups, i.e., showed a favorable factor structure for males, females, under and over 25 years of age. For the configural invariance, the model settings above the acceptance margins for the nested groups made up of the sexes (R-CFI $=0.939$, RRMSEA $=0.060 \mathrm{CI} 90 \%=0.051-0.068)$ and ages $(\mathrm{R}-\mathrm{CFI}=$ 0.929$, R-RMSEA $=0.058 \mathrm{CI} 90 \%=0.050-0.067)$, it can be stated that the unrestricted models were equivalent in the base configural model.

Once the restriction on factor loads was imposed, in the metric invariance test, differences were obtained $\Delta \mathrm{CFI} \leq$ 0.01 and $\triangle$ RMSEA $\leq 0.015$, which indicated that factor loads are invariant between groups. The following restriction was imposed on the intercepts to identify scalar (strong) invariance. The values indicated that the nested groups were invariant, i.e. the response and structure profiles are similar between the groups. Subsequently, a final restriction was implemented in the structural wastes to identify the strict invariance, the resulting values also indicated invariance, which showed that the groups were equivalent among their error variances.

Table 2. Invariance model fit parameters of the ARS across groups by sex and age.

\begin{tabular}{|c|c|c|c|c|c|c|c|c|c|c|}
\hline Groups and invariance & $\chi^{2}$ & S-B $\chi^{2}$ & $\mathrm{df}$ & R-TLI & R-CFI & R-RMSEA (CI90\%) & SRMR & $\Delta \mathrm{S}-\mathrm{B} \chi^{2}$ & $\Delta \mathrm{CFI}$ & $\Delta$ R-RMSEA \\
\hline Female & $404.285 * * *$ & $276.744 * * *$ & 144 & 0.928 & 0.939 & $0.060(0.049-0.070)$ & 0.047 & & & \\
\hline Male & $348.471 * * *$ & $228.260 * * *$ & 144 & 0.927 & 0.938 & $0.060(0.044-0.074)$ & 0.053 & & & \\
\hline Configural invariance & $752.756 * * *$ & $503.936 * * *$ & 288 & 0.927 & 0.939 & $0.060(0.051-0.068)$ & 0.049 & - & - & - \\
\hline Metric invariance & $769.304 * * *$ & $515.074 * * *$ & 303 & 0.932 & 0.940 & $0.058(0.049-0.066)$ & 0.055 & 11.138 & 0.001 & -0.002 \\
\hline Scalar invariance & $794.702 * * *$ & $543.313 * * *$ & 318 & 0.933 & 0.938 & $0.057(0.049-0.065)$ & 0.056 & 30.290 & -0.002 & 0.000 \\
\hline Strict invariance & $836.265^{* * *}$ & $564.488 * * *$ & 337 & 0.935 & 0.936 & $0.056(0.048-0.064)$ & 0.058 & 23.083 & -0.001 & -0.001 \\
\hline Under 25 years old & $327.689 * * *$ & $246.348^{* *}$ & 144 & 0.927 & 0.938 & $0.058(0.046-0.071)$ & 0.048 & & & \\
\hline Over 25 years old & $408.565^{* * *}$ & $249.943 * * *$ & 144 & 0.930 & 0.941 & $0.058(0.046-0.070)$ & 0.050 & & & \\
\hline Configural invariance & $736.254 * * *$ & $496.659 * * *$ & 288 & 0.929 & 0.940 & $0.058(0.050-0.067)$ & 0.049 & - & - & - \\
\hline Metric invariance & $763.014 * * *$ & $513.242 * * *$ & 303 & 0.931 & 0.939 & $0.057(0.049-0.066)$ & 0.059 & 17.146 & -0.001 & -0.001 \\
\hline Scalar invariance & $776.317^{* * *}$ & $530.510 * * *$ & 318 & 0.935 & 0.940 & $0.056(0.047-0.064)$ & 0.060 & 13.234 & 0.000 & -0.002 \\
\hline Strict invariance & $876.183^{* * *}$ & $589.546 * * *$ & 337 & 0.926 & 0.927 & $0.059(0.051-0.067)$ & 0.062 & 53.411 & -0.012 & 0.004 \\
\hline
\end{tabular}

\section{The validity of concurrent criteria}

We carried out bivariate correlations between the dimensions of rumination anger and the measures of reactive, proactive and combined aggression. We also established a model of multiple regression by successive steps having as a criterion variable the measures of aggression, and the subscales of rumination anger as predictors. Table 3 shows the statistically significant associations $(p<.01)$ obtained between total measures of rumination-irrigation and aggression as evidence of the validity of the concurrent criterion. It is noted that the highest association was with reactive and combined aggres- sion $(r=.53$ and $r=.49)$, and slightly lower with the ARS subscales. In proactive aggression, partnership measures were lower in the total and subscales ( $r$ between .26 and .36 ). In the successive step regression models, the highest determination coefficients were for reactive and combined aggression $\left(\mathrm{AR}^{2}=.277\right.$ and $\left..243, p<.01\right)$, and significantly low for proactive aggression $\left(\mathrm{AR}^{2}=.117, p<.01\right)$, which made evident the predictive capacity of the instrument, mainly in the forms of impulsive, hostile and emotional aggression, according to the AA, AM and TR subscales, while UC for proactive aggression. 
Table 3. Zero-order correlations and multiple linear regressions by successive steps between anger-rumination and aggression measures.

\begin{tabular}{|c|c|c|c|}
\hline & Reactive agression & Proactive agression & Total agresión \\
\hline ARS & $r=.53 * *$ & $r=.34 * *$ & $r=.49 * *$ \\
\hline $\mathrm{AA}$ & $r=.49 * *$ & $r=.30^{* *}$ & $r=.45^{* *}$ \\
\hline $\mathrm{AM}$ & $r=.46^{* *}$ & $r=.27 * *$ & $r=.42^{* *}$ \\
\hline TR & $r=.42^{* *}$ & $r=.36^{* *}$ & $r=.43^{* *}$ \\
\hline $\mathrm{UC}$ & $r=.42 * *$ & $r=.26^{* *}$ & $r=.39 * *$ \\
\hline Regression model & $A R^{2}=.277$ & $A \mathrm{R}^{2}=.117$ & $A \mathrm{R}^{2}=.243$ \\
\hline (Total scores) & RMSE $=3.131$ & RMSE $=2.485$ & RMSE $=5.015$ \\
\hline & intercept 10.995 & intercept 11.104 & intercept 22.099 \\
\hline & $\begin{array}{l}\text { ARS U } \beta=0.283(\text { IC95\% }=0.174- \\
0.223), \beta=.527\end{array}$ & $\begin{array}{l}\text { ARS U } \beta=0.093(\text { IC95\% }=0.073- \\
0.113) \beta=.344\end{array}$ & $\begin{array}{l}\text { ARS U } \beta=0.291(\text { IC95 } \%= \\
0.252-0.331), \beta=.494\end{array}$ \\
\hline \multirow{6}{*}{$\begin{array}{l}\text { Regression model } \\
\text { (Subscales scores) }\end{array}$} & $A R^{2}=.273^{* *}$ & $A \mathrm{R}^{2}=.134 * *$ & $A R^{2}=.244^{* *}$ \\
\hline & $R M S E=3.140$ & RMSE $=2.461$ & RMSE $=5.013$ \\
\hline & intercept 11.274 & intercept 11.095 & intercept 22.430 \\
\hline & $\begin{array}{l}\text { AA U } \beta=0.283(\text { IC95\% } \%=0.179-0.387) \\
\beta=.266\end{array}$ & $\begin{array}{l}\text { TR U } \beta=0.346(\text { IC95 } \%=0.250- \\
0.441), \beta=.301\end{array}$ & $\begin{array}{l}\mathrm{AA} \mathrm{U} \beta=0.359(I C 95 \%= \\
0.193-0.525), \beta=.216\end{array}$ \\
\hline & $\begin{array}{l}\mathrm{AM} \mathrm{U} \beta=0.226(\mathrm{IC9} \%=0.114-0.339) \\
\beta=0.191\end{array}$ & $\begin{array}{l}\mathrm{UC} \mathrm{U} \beta=0.115(\mathrm{IC95} \%=0.030- \\
0.200), \beta=0.113\end{array}$ & $\begin{array}{l}\text { TR } \beta=0.539(\text { IC95\% }=0.314 \\
-0.765), \beta=.215\end{array}$ \\
\hline & \multicolumn{2}{|l|}{$\begin{array}{l}\text { TR U } \beta=0.228(I C 95 \%=0.087-0.370), \\
\beta=0.143\end{array}$} & $\begin{array}{l}\mathrm{AM} \beta=0.261(\mathrm{IC95} \%=0.081 \\
-0.441), \beta=.141\end{array}$ \\
\hline
\end{tabular}

Nota: Unstandarized Beta $(\mathrm{U} \beta)$, Standarized Beta $(\beta)$. $* * p<.001$

\section{Reliability of the ARS}

Finally, the reliability indicators according to the internal consistency values of the ARS were excellent for the entire test $(\alpha=.927, \omega=.928)$ and favorable for the $\mathrm{AM}(\alpha=.811$, $\omega=.812)$ and $\mathrm{AA}(\alpha=.875, \omega=.876)$ subscales and acceptable for TR $(\alpha=.744, \omega=.770)$ and UC $(\alpha=.754, \omega=$ .756 ), which are similar to the results reported in the original Sukhodolsky et al. (2001).

\section{Discussion}

The objective of the study was to analyze the factor structure of the ARS and its invariance according to the female and male sex, and the age groups under and over 25 years, in a Colombian sample. According to the data obtained in the verification of the evaluated models, as well as in the analysis of the structure of the test imposing sequential restrictions, it can be affirmed that the objective was achieved.

This study confirmed that the structure of four correlated factors and residual covariances has the best adjustment indicators concerning the one-dimensional models and the other models proposed in the Spanish version with a Mexican sample (Ortega-Andrade et al, 2017) in addition to the original (Sukhodolsky et al., 2001), which also coincides with previous cross-cultural reports in different countries (e.g. Besharat, 2011; Magán-Uceda et al., 2016; Maxwell et al., 2005; Reynes et al., 2013; Satici, 2014).

In this study, an additional residual covariance was added to the original one between items 10 ("I have had moments when I could not stop worrying about a particular conflict") and 16 ("When someone makes me angry I cannot stop thinking about how to get back at this person"), this addition is valid since they are part of the UC factor, related to the temporality of the evaluated construct.

Thus, these additional covariances are consistent with the phenomenon of anger rumination that includes the reexperimentation of the anger event in a previous (causes) and future (retaliation) time dimension, as part of a onedimensional construct (Spielberger, 1988; Sukhodolsky et al, 2001), which has even been suggested to have a higher-order structure of rumination, including simultaneous emotional and affective measures according to the general style of ruminative response (Lyubomirsky \& Nolen-Hoeksema, 1993), or it is a temporal moderator that appears in various behaviors both healthy and pathological (Riley, Park, \& Laurenceau, 2018).

These theoretical considerations can show the high internal consistency obtained for the whole instrument, according to the reliability measures of the ARS, the values were favorable and coincided with those reported in its original development (Sukhodolsky et al., 2001) and were above the study carried out in Mexico (Ortega-Andrade et al., 2017). These internal consistency values show the viable use of the test in the Colombian context, a contribution that constitutes an advance in the study of externalizing psychopathologies in the national context.

Additionally, the test was invariant between the male and female sexes, as well as in the under- and over-25-year-old samples, so it can be inferred that the cognitive processes as- 
sociated with anger, such as the ruminative response, is cross-sectional in the population and does not show significant variations in ARS scores, unlike previous studies of its adaptation in other countries where differential scores were reported in women (Maxwell et al, 2005; Ortega-Andrade et al., 2017; Sukhodolsky et al., 2001; White \& Turner, 2014). These findings allow us to conclude that the ARS is an instrument that can be used without distinguishing differential scores between sexes or ages; however, these assertions will need to be corroborated in subsequent studies, preferably of a longitudinal nature.

Likewise, the significant correlations between angerrumination measures and reactive and proactive aggression, allow us to affirm that the ARS shows a favorable predictive capacity given that the direct association between these measures coincides with the reports of transdiagnostic studies on externalizing psychopathologies, particularly aggressive behaviors (Peters et al., 2015; White \& Turner, 2014), which can increase and be maintained even 24 hours later (Bushman \& Gibson, 2011). However, the values obtained in the determination coefficients for proactive aggression were low, which shows that rumination anger hardly converges with this type of aggression, which has been associated with psychopathic profiles (White \& Frick, 2010) and its relationship seems to be mediated and moderated by other variables such as exerted control, age, sex, among others (e.g. White \& Turner, 2014).

In this regard, anger rumination has had a high adaptive value in human history by serving on the one hand as a mechanism of regulation of aggressive impulses (reactive aggression), and on the other hand to establish improvements in social relations through forgiveness (low proactive aggression) (Denson, 2012); however, although the correlations were significant, it is not possible to undermine the scope of these hypotheses of evolutionary nature. Therefore, it can be affirmed that the ARS showed significant predictive capacity in a multiple linear regression model except for proactive ag-

\section{References}

Andreu, J., Peña, M., \& Ramírez, J. (2009). Cuestionario de agresión reactiva y proactiva: Un instrumento de medida de la agresión en adolescentes [Reactive and proactive aggression questionnaire: an instrument for measuring aggression in adolescents]. Revista de Psicopatología y Psicología

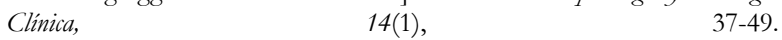
http://www.aepcp.net/arc/(4)_2009(1)_Andreu_Pena_Ramirez.pdf

Anestis, M. D., Anestis, J. C., Selby, E. A., \& Joiner, T. E. (2009). Anger rumination across forms of aggression. Personality and Individual Differences, 46(2), 192-196. doi:10.1016/j.paid.2008.09.026

Asociación Médica Mundial [WMA] (2017). Declaración de Helsinki de la AMM - Principios éticos para las investigaciones médicas en seres bumanos LWMA Helsinki Declaration - Ethical Principles for Medical Research in Humans]. Brasil: Autor. Available at https://www.wma.net/es/policiespost/declaracion-de-helsinki-de-la-amm-principios-eticos-para-lasinvestigaciones-medicas-en-seres-humanos/

Besharat, M. A. (2011). Factorial and cross-cultural validity of a Farsi version of the Anger Rumination Scale. Psychological Reports, 108(1), 317 328. doi:10.2466/02.08.09.PR0.108.1.317-328 gression, and constitutes new evidence of the validity of the convergent criterion of the instrument herein analyzed, although it is necessary to further explore these future hypotheses in transdiagnostic models based on this construct (du Pont et al., 2017).

This study had limitations that should be taken into account in further research. The first is because it has a crosssectional design, although it may be appropriate for psychometric analysis. It has limitations, such as not allowing the repeated investigation of self-reported measures, the stability of scores in a test-retest and the monitoring of age changes, which may be more accurate when combined with complementary methods to psychometric methods, such as latent classes, intercepts and scalar invariances by threshold methods for four-option Likert scales (Pendergast, von der Embse, Kilgus, \& Eklund, 2017), in addition to longitudinal monitoring (Hickendorff, Edelsbrunner, McMullen, Schneider, \& Trezise, 2018). Another limitation was not having a sample with high scores in the aggressive behaviors, consolidating a clinical sample that would allow establishing differential hypotheses in the scores and having elaborated a sensitivity and specificity analysis, a contribution of the study that would allow making predictive analyses based on the measures of rumination anger in the development of a psychological treatment.

In conclusion, the ARS is a test that coincides with the original factorial structure of four correlated components, and which also showed favorable indicators of reliability and validity which makes it highly recommended for use in the Colombian context and will serve as a reference for future studies in Spanish-speaking countries.

Note.- Document derived from the doctoral thesis project "Transdiagnostic Model for Antisocial Disorders in Adolescence and Youth," from the International Doctoral School (EIDUAL, for its Spanish acronym) at the University of Almería.

Bushman, B. J., \& Gibson, B. (2011). Violent video games cause an increase in aggression long after the game has been turned off. Social Psychological and Personality Science, 2(1), 29-32. doi:10.1177/1948550610379506

Byrne, B. M. (2008) Testing for multigroup equivalence of a measuring instrument a walk through the process. Psicothema, 20(4), 872-882. Available at http://www.psicothema.com/pdf/3569.pdf

Chen, F. F. (2007). Sensitivity of goodness of fit indexes to lack of measurement invariance. Structural Equation Modeling: A Multidisciplinary Journal, 14(3), 464-504. doi: 10.1080/10705510701301834

Cheung, G. W., \& Rensvold, R. B. (2002). Evaluating goodness-of-fit indexes for testing measurement invariance. Structural Equation Modeling, 9(2), 233-255. doi:10.1207/S15328007SEM0902_5

Denson, T. F. (2012). The multiple systems model of angry rumination. Personality and Social Psychology Review, 17(2), 103-123. doi:10.1177/1088868312467086

du Pont, A., Rhee, S. H., Corley, R. P., Hewitt, J. K., \& Friedman, N. P. (2017). Rumination and psychopathology: Are anger and depressive rumination differentially associated with internalizing and externalizing 
psychopathology? Clinical Psychological Science, 6(1), 18-31. doi:10.1177/2167702617720747

García-Sancho, E., Salguero, J. M., \& Fernández-Berrocal, P. (2016). Angry rumination as a mediator of the relationship between ability emotional intelligence and various types of aggression. Personality and Individual Differences, 89, 143-147. doi:10.1016/j.paid.2015.10.007

Guerra, R. C., \& White, B. A. (2017). Psychopathy and functions of aggression in emerging adulthood: moderation by anger rumination and gender. Journal of Psychopathology and Behavioral Assessment, 39(1), 35-45. doi:10.1007/s10862-016-9563-9

Hickendorff, M., Edelsbrunner, P. A., McMullen, J., Schneider, M., \& Trezise, K. (2018). Informative tools for characterizing individual differences in learning: Latent class, latent profile, and latent transition analysis. Learning and Individual Differences, 66, 4-15. doi:10.1016/j.lindif.2017.11.001

Hu, L., \& Bentler, P. M. (1999). Cutoff criteria for fit indexes in covariance structure analysis: Conventional criteria versus new alternatives. Structural Equation Modeling: A multidisciplinary Journal, 6, 1-55. doi:10.1080/10705519909540118

Kahn, J. H. (2006). Factor analysis in counseling psychology research, training, and practice: Principles, advances, and applications. The Counseling Psychologist, 34(5), 684-718. doi:10.1177/0011000006286347

Li-Chung, L., Po-Hsien, H., \& Li-Jen, W. (2017). Selecting path models in SEM: A comparison of model selection criteria. Structural Equation Modeling: A Multidisciplinary Journal, 24(6), 855-869. doi:10.1080/10705511.2017.1363652

Lyubomirsky, S., \& Nolen-Hoeksema, S. (1993). Self-perpetuating properties of dysphoric rumination. Journal of Personality and Social Psychology, 65(2), 339-349. doi:10.1037/0022-3514.65.2.339

Magán-Uceda, I., Lozano-Bleda, J. H., Pérez-Nieto, M. A., Sukhodolsky, D. G., \& Escalona-Martínez, A. (2016). Psychometric properties of the Spanish adaptation of the Anger Rumination Scale: Evidence of reliability and validity in the general population. The Spanish Journal of Psycbology, 19(E17), 1-9. doi:10.1017/sip.2016.17

Martino, F., Caselli, G., Berardi, D., Fiore, F., Marino, E., Menchetti, M., ... Sassaroli, S. (2015). Anger rumination and aggressive behaviour in borderline personality disorder. Personality and Mental Health, 9(4), 277-287. doi: $10.1002 /$ pmh. 1310

Maxwell, J. P., Sukhodolsky, D. G., Chow, C. C. F., \& Wong, C. F. C. (2005). Anger rumination in Hong Kong and Great Britain: Validation of the scale and a cross-cultural comparison. Personality and Individual Differences, 39(6), 1147-1157. doi:10.1016/j.paid.2005.03.022

McLaughlin, K. A., Aldao, A., Wisco, B. E., \& Hilt, L. M. (2014). Rumination as a transdiagnostic factor underlying transitions between internalizing symptoms and aggressive behavior in early adolescents. Journal of Abnormal Psychology, 123(1), 13-23. doi:10.1037/a0035358

Meredith, W. (1993). Measurement invariance, factor analysis and factorial invariance. Psychometrika, 58(4), 525-543. doi:10.1007/bf02294825

Ortega-Andrade, N., Alcázar-Olán, R., Matías, O. M., Rivera-Guerrero, A., \& Domínguez-Espinosa, A. (2017). Anger Rumination Scale: Validation in Mexico. The Spanish Journal of Psychology, 20(e1), 1-9. doi:10.1017/sjp.2016.105

Pendergast, L. L., von der Embse, N., Kilgus, S. P., \& Eklund, K. R. (2017). Measurement equivalence: A non-technical primer on categorical multi-group confirmatory factor analysis in school psychology. Journal of School Psychology, 60, 65-82. doi:10.1016/j.jsp.2016.11.002

Peters, J. R., Smart, L. M., Eisenlohr-Moul, T. A., Geiger, P. J., Smith, G. T. \& Baer, R. A. (2015). Anger rumination as a mediator of the relationship between mindfulness and aggression: The utility of a multidimen- sional mindfulness model. Journal of Clinical Psychology, 71(9), 871-884. doi:10.1002/jclp.22189

Raine, A., Dodge, H., Loeber, R., Gatzke-Kopp, L., Lynam, D., Reynolds, C., ... Liu, J. (2006). The Reactive - Proactive Aggression Questionnaire: Differential correlates of reactive and proactive aggression in adolescent boys. Aggressive Behavior, 32(2), 159-171. doi:10.1002/ab.20115

Reynes, E, Berthouze-Aranda, S. E, Guillet-Descas, E, Chabaud, P. \& Deflandre, A. (2013). French validation of the Anger Rumination Scale. Encephale, 39(5), 339-346. doi:10.1016/j.encep.2012.11.006

Rhemtulla, M., Brosseau-Liard, P. E., \& Savalei, V. (2012). When can categorical variables be treated as continuous? A comparison of robust continuous and categorical SEM estimation methods under suboptimal conditions. Psychological Methods, 17, 354-373. doi:10.1037/a0029315

Riley, K. E., Park, C. L., \& Laurenceau, J. (2018). A Daily Diary Study of Rumination and Health Behaviors: Modeling Moderators and Mediators. Annals of Behavioral Medicine: a publication of the Society of Behavioral Medicine, 53(8), 743-755. doi:10.1093/abm/kay081

Rosseel, Y. (2012). lavaan: An R Package for Structural Equation Modeling. Journal of Statistical Software, 48(2), 1-36. Available at http://www.jstatsoft.org/v48/i02/

Satici, S. A. (2014). Anger Rumination Scale: Psychometric properties of the Turkish version. Anatolian Journal of Psychiatry, 15(4), 328-334. doi:10.5455/apd.42654

Satorra, A., \& Bentler, P. M. (2010). Ensuring Positiveness of the Scaled Difference Chi-square Test Statistic. Psychometrika, 75(2), 243-248. doi:10.1007/s11336-009-9135-y

Spielberger, C. D. (1988). Manual for the State-Trait Anger Expression Inventory (STAXI). Odessa, FL: Psychological Assessment Resources.

Sukhodolsky, D. G., Golub, A., \& Cromwell, E. N. (2001). Development and validation of the anger rumination scale. Personality and Individual Differences, 31(5), 689-700. doi:10.1016/s0191-8869(00)00171-9

Takebe, M., Takahashi, F., \& Sato, H. (2016). Anger rumination as a risk factor for trait anger and anger-in: A longitudinal study. Personality and Individual Differences, 101, 451-455. doi:10.1016/j.paid.2016.06.038

Wang, X., Yang, L., Yang, J., Gao, L., Zhao, F., Xie, X., \& Lei, L. (2018). Trait anger and aggression: A moderated mediation model of anger rumination and moral disengagement. Personality and Individual Differences, 125, 44-49. doi:10.1016/i.paid.2017.12.029

White, S. T., \& Frick, P. J. (2010). Callous - unemotional traits and their importance to causal models of severe antisocial behavior in youths. In R.T. Salekin and D.T. Lynam (eds), Handbook of child and adolescent psychology (pp. 135-156). Nueva York: The Gilford Press.

White, B. A., \& Turner, K. A. (2014). Anger rumination and effortful control: Mediation effects on reactive but not proactive aggression. Personality and Individual Differences, 56, 186-189. doi:10.1016/i.paid.2013.08.012

Wong, T. K. Y., Konishi, C., \& Zhao, K. (2018). Anger and anger regulation among adolescents: A consideration of sex and age differences. Canadian Journal of Behavioural Science / Revue canadienne des sciences du comportement, 50(1), 1-8. doi:10.1037/cbs0000089

Yang, Y. (2003). Regression with multiple candidate models: Selecting or mixing? Statistica Sinica, 13(3), 783-809. http://www3.stat.sinica.edu.tw/statistica/oldpdf/a13n313.pdf

Yuan, K. H., Marshall, L. L., \& Bentler, P. M. (2002). A unified approach to exploratory factor analysis with missing data, nonnormal data, and in the presence of outliers. Psychometrika, 67(1), 95-121. doi:10.1007/bf02294711 